\title{
Postpartum Metabolism: How Does It Change from Pregnancy and What are the Potential Implications?
}

\author{
Rachel A Tinius $\mathbb{D}^{\prime}$ \\ Kristin Yoho' \\ Maire M Blankenship ${ }^{2}$ \\ Jill M Maples (D) $^{3}$
}

'School of Kinesiology, Recreation, and Sport, Western Kentucky University, Bowling Green, KY, 42I0I, USA; ${ }^{2}$ School of Nursing and Allied Health, Western Kentucky University, Bowling Green, KY, 42I0I, USA; ${ }^{3}$ Department of Obstetrics and Gynecology, University of Tennessee Graduate School of Medicine, Knoxville, TN, 37920, USA
Correspondence: Rachel A Tinius School of Kinesiology, Recreation, and Sport, Western Kentucky University, Bowling Green, KY, 42 I0I, USA

Tel + I 270-745-5026

Email Rachel.tinius@wku.edu
Background: Metabolic dysfunction after pregnancy may have serious consequences for a new mother. The purpose of the study was to characterize basic changes that occur in metabolic profiles from late pregnancy through 4-6 months postpartum. A secondary purpose was to determine metabolic factors that may be contributing to postpartum weight retention.

Methods: Participants $(n=25)$ came in for 2 visits: late pregnancy $(\sim 34$ weeks gestation $)$ and postpartum (4-6 months). Resting metabolic rate (RMR), respiratory quotient (RQ), and substrate oxidation values were assessed for 15 minutes during fasted conditions. Blood was drawn and skinfold anthropometry was performed to assess additional outcomes (inflammation, insulin resistance, lipid profiles, body composition). The participants completed a number of surveys that examined other lifestyle and demographic data of interest. At the postpartum visit, additional assessments regarding sleep and breastfeeding habits were administered.

Results: RMR was lower during postpartum $(1517.2 \pm 225.1 \mathrm{kcal} /$ day $)$ compared to pregnancy $(1867.9 \pm 302.6 \mathrm{kcal} /$ day $)(\mathrm{p}<0.001)$, and remained lower when expressing $\mathrm{RMR}$ per $\mathrm{kg}$ body weight (postpartum: $22.3 \pm 2.7$ vs pregnant: $23.7 \pm 3.4 \mathrm{kcal} / \mathrm{kg},(\mathrm{p}=0.034)$. Relative $\mathrm{RMR}$ (RMR per kg body weight) was negatively correlated to insulin resistance (HOMA-IR) during postpartum $(r=-.463, \mathrm{p}=0.034)$. Maternal HOMA-IR, inflammation (CRP), triglycerides (TAG), and carbohydrate oxidation were all positively correlated to postpartum weight retention (HOMA-IR: $\mathrm{r}=0.617, \mathrm{p}=0.004$; CRP: $\mathrm{r}=0.477, \mathrm{p}=0.039$, TAG: $\mathrm{r}=0.463$, $\mathrm{p}=0.040$; Carbohydrate Oxidation: $(\mathrm{r}=0.469, \mathrm{p}=0.018)$.

Conclusion: Metabolic rate is lower during postpartum compared to pregnancy, and may be connected to insulin resistance. Maternal insulin resistance, inflammation, blood lipids, and substrate metabolism are all related to postpartum weight retention.

Keywords: postnatal, metabolic rate, insulin resistance, inflammation

\section{Introduction}

Pregnancy and postpartum are two critical time periods in a woman's life. Metabolic dysfunction during and after pregnancy may have serious consequences for a mother and her baby. There is growing concern for maintenance of healthy metabolic profiles during pregnancy and postpartum as recent data suggests the development of obesity and/or diabetes during reproductive years (ie pregnancy and postpartum) is at an alltime high. ${ }^{1-4}$ The seriousness of the issue is elucidated by current data that suggests at six months postpartum approximately $50 \%$ of women retain $\geq 10$ pounds, approximately $25 \%$ retain $\geq 20$ pounds, and many of these women gain additional weight 
during the first postpartum year. ${ }^{5,6}$ Postpartum weight retention is an independent risk factor for long-term maternal health consequences, including obesity, type II diabetes, and cardiovascular disease. ${ }^{7}$ Therefore, there is an urgent need to understand the mechanisms contributing to weight retention and unfavorable metabolic health during the postpartum period.

Metabolic health during pregnancy has been extensively studied. ${ }^{8}$ However, research on metabolic changes that occur during the postpartum period is limited. The research is similar to clinical care where following parturition, the focus of medical attention shifts to the health of the infant, while maternal metabolic health status is often disregarded. ${ }^{9}$ Poorer metabolic function during this time period may have serious consequences for a new mother. Understanding the basic metabolic changes that occur among postpartum women is critically important to the design of targeted future intervention strategies in order to potentially influence the cycle of weight gain and retention. ${ }^{10}$ Further, metabolic health during these critical time periods may serve as clues to future health and chronic disease risk. ${ }^{11,12}$

Therefore, the purpose of the study was to characterize basic changes that occur in metabolic profiles from late pregnancy through 4-6 months postpartum. A secondary purpose was to examine metabolic factors that may be contributing to weight retention.

\section{Materials and Methods}

\section{Participants}

Healthy pregnant women were recruited between 32 and 34 weeks of gestation as part of a previously published pregnancy study. ${ }^{13}$ After completing the pregnancy visit between 32 and 38 weeks gestation, all women were recontacted to participate in the postpartum follow-up study between 4 and 6 months. All participants were considered eligible unless they had developed any new medical conditions that could impact metabolic health. All procedures were approved by the Institutional Review Board of Western Kentucky University (IRB \#16-229 (pregnancy visit) and IRB \#17-412 (postpartum visit)). The participants provided written informed consent prior to each visit and received compensation after completing each visit.

\section{Procedures}

Participants came in for two visits - one during late pregnancy ( $\sim 34$ weeks gestation) and the other between 4 and 6 months postpartum. The study visit procedures were exactly the same for each timepoint. Each participant was given written instructions consuming a standardized diet the night before the visit; these varied for each woman depending on her pre-pregnancy weight status (ie lean, overweight, or obese). The instructions included a detailed "menu" from which participants could select the food items they preferred but in a specific portion size. These instructions included a dinner that was to be eaten around 6:00 PM and a snack that was to be eaten around 9:00 PM the night before the visit. The standardized meal consisted of approximately $50 \%$ carbohydrates, $30 \%$ fats, and $20 \%$ protein. The participants were expected to eat no later than 10:00 PM the night before and come to the study visit completely fasted.

At the start of each visit, baseline vitals were taken. After vitals were collected, a nurse practitioner inserted an IV catheter into the antecubital space. Approximately $8 \mathrm{~mL}$ of blood was drawn and divided equally between a purple-top EDTA Vacutainer tube and a green-top lithium heparin tube. The blood was then centrifuged, separated into its plasma and red blood cell components and aliquoted into microcentrifuge tubes. The tubes were kept frozen at $-80{ }^{\circ} \mathrm{C}$ for subsequent analyses.

After the blood draw, the ParvoMedics TrueOne 2400 metabolic cart was used to measure resting metabolic rate. The participants were instructed to lay still and quiet while propped up on a plinth and the hood/canopy was placed over their head and sealed. Metabolic rate was recorded for 15 minutes. The data collected by the metabolic cart included resting metabolic rate (RMR), respiratory quotient (RQ), volume of oxygen consumed $\left(\mathrm{VO}_{2}\right)$, and volume of carbon dioxide produced $\left(\mathrm{VCO}_{2}\right)$. These values were compiled throughout the 15-minute duration and were averaged to determine resting metabolic values for each participant. $\mathrm{VO}_{2}$ and $\mathrm{VCO}_{2}$ were used to determine lipid and carbohydrate oxidation values using standardized equations. $^{14}$

Skinfold anthropometry was then performed to determine body fat percentage of the participants. Folds of the skin at seven predetermined sites were pressed with a caliper (Harpenden Skinfolds Caliper, Baty International, United Kingdom) and the thickness of each fold was recorded. However, only three sites (triceps, subscapular, and suprailiac) were used for analyses based on an equation from Hutson et al. ${ }^{15}$ This equation was chosen as typical skinfold measurements significantly change shortly after pregnancy despite minimal or no actual changes in fat mass, which suggests an adjustment 
in the distribution of body fat rather than an actual change in body composition. ${ }^{16,17}$ The sites chosen as part of this equation ${ }^{15}$ are less impacted by the redistribution of fat that many women experience during and shortly after pregnancy (eg abdominal skinfold). Postpartum weight retention (PPWR) was determined by subtracting prepregnancy weight from weight at the postpartum study visit.

Each participant was also given the NIH Dietary History Questionnaire II to complete in order to account for diet. Participants wore an Actigraph GTX9 Link accelerometer (Actigraph LLC, Pensacola, FL) on the nondominant wrist for seven consecutive days in order to account for physical activity levels. Additional questionnaires were given to the participant at the postpartum visit in order to acount for other salient factors (ie sleep, breastfeeding status, and mental health) that could impact metabolism during the postpartum period. These included the Pittsburgh Sleep Quality Index, ${ }^{18}$ the Center for Disease Control's breastfeeding and infant feeding practices survey (5-month), ${ }^{19}$ and the Edinburgh Postpartum Depression Survey. ${ }^{20}$

\section{Statistical Analyses}

Normality of the distribution for each variable was tested using Kolmogorov-Smirnov tests. Data that were not normally distributed were log-transformed. Paired $t$-tests were used to compare outcomes between timepoints (pregnant and postpartum). Pearson product-moment correlation coefficients for normally distributed variables or Spearman's rank-order correlation coefficient for non-normally distributed variables were used to assess the degree of the relationships between variables. All data analyses were conducted using IBM SPSS Statistics, Version 27 (Armonk, New York). Sample size was not calculated as it was dictated by the number of women in the pregnancy study able to come back for the postpartum visit.

\section{Results}

Descriptive statistics and metabolic variables can be found in Table 1. Pregnant women had higher body weight than postpartum women (as to be expected during late pregnancy). Insulin, C-reactive protein (CRP), and triglycerides (TAG) values were higher, and glucose values were lower among pregnant women compared to postpartum women. Lipid oxidation rate and resting metabolic rate were higher during pregnancy compared to postpartum. Resting metabolic rate remained significantly higher during pregnancy even when controlling for body weight, while lipid oxidation rate did not $(\mathrm{p}=0.436)$. The majority of postpartum women were lactating at the time of data collection $(72 \%)$ (Table 1$)$.

Because of the well-established changes in metabolism due to lactation, ${ }^{21}$ data among lactating and non-lactating women were also compared. RMR relative to body weight was significantly higher among lactating women compared to non-lactating women (lactating: $22.8 \pm 2.6 \mathrm{kcal}$ vs nonlactating: $20.4 \pm 2.3, \mathrm{p}=0.046)$. Similarly, lipid oxidation rate was lower among women who are lactating vs nonlactating women (lactating: $0.0564 \pm 0.15$ vs non-lactating: $0.0845 \pm 0.0189, \mathrm{p}=0.001)$; however, this was no longer significant when controlling for body weight as nonlactating women were, on average, nearly $15 \mathrm{~kg}$ heavier than non-lactating women.

Metabolic characteristics at 4-6 months postpartum were linked to PPWR. RMR was positively correlated to postpartum weight retention $(\mathrm{r}=0.606, \mathrm{p}=0.001)$; however, when expressed per unit body weight this association disappeared $(\mathrm{r}=-0.088, \mathrm{p}=0.675)$. Relative RMR (RMR per $\mathrm{kg}$ body weight) was negatively correlated to HOMA-IR $(r=-.463$, $\mathrm{p}=0.034$ ) (Figure 1). Several other metabolic outcomes were positively correlated to PPWR. Absolute carbohydrate oxidation, maternal insulin resistance (ie HOMA-IR), inflammation (CRP), and triglycerides (TAG) were positively correlated to PPWR (Carbohydrate Oxidation: $\mathrm{r}=0.469$, $\mathrm{p}=0.018 ;$ HOMA-IR: $\mathrm{r}=0.617, \mathrm{p}=0.004 ; \mathrm{CRP}: \mathrm{r}=0.477$, $\mathrm{p}=0.039$, TAG: $\mathrm{r}=0.463, \mathrm{p}=0.040$ ) (Figure 2). When controlling for pre-pregnancy BMI, PPWR remained positively correlated with carbohydrate oxidation and HOMA-IR (carbohydrate oxidation: $\mathrm{r}=0.538, \mathrm{p}=0.021$; HOMA-IR: $\mathrm{r}=0.601$, $\mathrm{p}=0.008$ ); however, the relationships between PPWR and CRP and TAG were no longer significant (CRP: $r=0.425$, $\mathrm{p}=0.078$, TAG: $\mathrm{r}=0.392, \mathrm{p}=0.197$ ).

\section{Discussion}

The main findings of the study were that resting metabolic rate (RMR) (expressed in both absolute and relative (to body weight) terms) was higher during pregnancy when compared to 4-6 months postpartum and that lower relative resting metabolic rate during postpartum may be connected to insulin resistance. In addition, maternal carbohydrate oxidation, insulin resistance, inflammation, and triglycerides were all found to be positively correlated to postpartum weight retention.

During late pregnancy, RMR values were higher than those measured at the postpartum visits. While body 
Table I Descriptive Statistics and Metabolic Factors During Late Pregnancy and 4-6 Months Postpartum

\begin{tabular}{|c|c|c|c|}
\hline & Pregnancy $(n=25)$ & Postpartum $(n=25)$ & p-value \\
\hline BMI $\left(\mathrm{kg} / \mathrm{m}^{2}\right)$ & 24.5 \pm 3.7 (pre-pregnancy BMI) & $25.5 \pm 4.4$ & \\
\hline \multicolumn{4}{|l|}{ BMI Classification (based on pre-pregnancy BMI) } \\
\hline Lean & $16(64 \%)$ & & \\
\hline Overweight & $7(28 \%)$ & & \\
\hline Obese & $2(8 \%)$ & & \\
\hline Age $(y)$ & $31.4 \pm 4.2$ & & \\
\hline Gestation age at visit (weeks) & $33.9 \pm 1.6$ & & \\
\hline \multicolumn{4}{|l|}{ Parity } \\
\hline Nulliparous & $16(64 \%)$ & & \\
\hline Multiparous & $9(36 \%)$ & & \\
\hline \multicolumn{4}{|l|}{ Lactation Status } \\
\hline Lactating & & 18 (72\%) & \\
\hline Not-Lactating & & $7(28 \%)$ & \\
\hline Weight $(\mathrm{kg})^{*}$ & $80.2 \pm 11.4$ & $69.6 \pm 13.1$ & $<0.001$ \\
\hline Body fat percentage ${ }^{15}(\%)$ & $26.8 \pm 7.5$ & $26.2 \pm 10.2$ & 0.632 \\
\hline Systolic blood pressure $(\mathrm{mmHg})$ & $122.1 \pm 15.2$ & $122.9 \pm 14.4$ & 0.801 \\
\hline Diastolic blood pressure $(\mathrm{mmHg})$ & $74.9 \pm 11.9$ & $78.2 \pm 9.0$ & 0.145 \\
\hline Resting heart rate (bpm) & $84.0 \pm 10.9$ & $74.4 \pm 12.9$ & $<0.001$ \\
\hline \multicolumn{4}{|l|}{ Physical activity levels } \\
\hline Sedentary (\%) & $56.4 \pm 9.4$ & $55.6 \pm 9.8$ & 0.692 \\
\hline Moderate (\%) & $12.0 \pm 4.1$ & $12.8 \pm 4.2$ & 0.338 \\
\hline \multicolumn{4}{|l|}{ Dietary intake } \\
\hline Energy (kcal/day) & $1972.7 \pm 8 \mid 8.0$ & $1844.0 \pm 973.5$ & 0.382 \\
\hline Fat $(g)$ & $85.3 \pm 45.2$ & $78.4 \pm 44.8$ & 0.301 \\
\hline Carb $(g)$ & $230.6 \pm 89.4$ & $213.3 \pm 112.7$ & 0.354 \\
\hline Protein $(\mathrm{g})$ & $81.2 \pm 40.3$ & $77.9 \pm 46.6$ & 0.652 \\
\hline $\mathrm{CRP}(\mathrm{mg} / \mathrm{L})^{*}$ & $4.2 \pm 2.6$ & $1.8 \pm 2.0$ & 0.001 \\
\hline Insulin $(\mathrm{uU} / \mathrm{mL})^{*}$ & $8.0 \pm 3.6$ & $5.8 \pm 3.1$ & 0.046 \\
\hline Glucose $(\mathrm{mg} / \mathrm{dL})^{*}$ & $80.2 \pm 8.1$ & $96.6 \pm 11.2$ & 0.089 \\
\hline HOMA-IR & $1.59 \pm 0.79$ & $1.27 \pm 0.74$ & 0.185 \\
\hline Free fatty acids (meq/L) & $0.43 \pm 0.15$ & $0.41 \pm 0.17$ & 0.803 \\
\hline Triglycerides (mg/dL)* & $207.5 \pm 73$ & $64.5 \pm 35.7$ & $<0.001$ \\
\hline Resting metabolic rate $(\mathrm{kcal})^{*}$ & $1867.9 \pm 302.6$ & $15 \mid 7.2 \pm 225.1$ & $<0.001$ \\
\hline RMR per $\mathrm{kg}$ body weight ( $\mathrm{kcal} / \mathrm{kg})^{*}$ & $23.7 \pm 3.4$ & $22.3 \pm 2.7$ & 0.034 \\
\hline Respiratory quotient & $0.8165 \pm 0.0594$ & $0.8291 \pm 0.04498$ & 0.418 \\
\hline Lipid oxidation rate $(\mathrm{g} / \mathrm{min})^{*}$ & $0.0793 \pm 0.0337$ & $0.0626 \pm 0.01932$ & 0.049 \\
\hline Lipid oxidation per $\mathrm{kg}$ body weight $(\mathrm{g} / \mathrm{kg} / \mathrm{min})$ & $0.010 \pm 0.0004$ & $0.009 \pm 0.0003$ & 0.436 \\
\hline Carbohydrate oxidation (g/min) & $0.1426 \pm 0.0556$ & $0.1276 \pm 0.05339$ & 0.340 \\
\hline Carbohydrate oxidation per $\mathrm{kg}$ body weight $(\mathrm{g} / \mathrm{kg} / \mathrm{min})$ & $0.0018 \pm 0.0008$ & $0.0019 \pm 0.0008$ & 0.761 \\
\hline
\end{tabular}

Note: ${ }^{*} p<0.05$.

weight is a factor known to impact RMR directly, 22 these changes persisted even when expressing RMR per kilogram of body weight. RMR per kilogram body weight was significantly higher during late pregnancy than in the 4-6 month postpartum period. The findings of this study are consistent with previous work that 


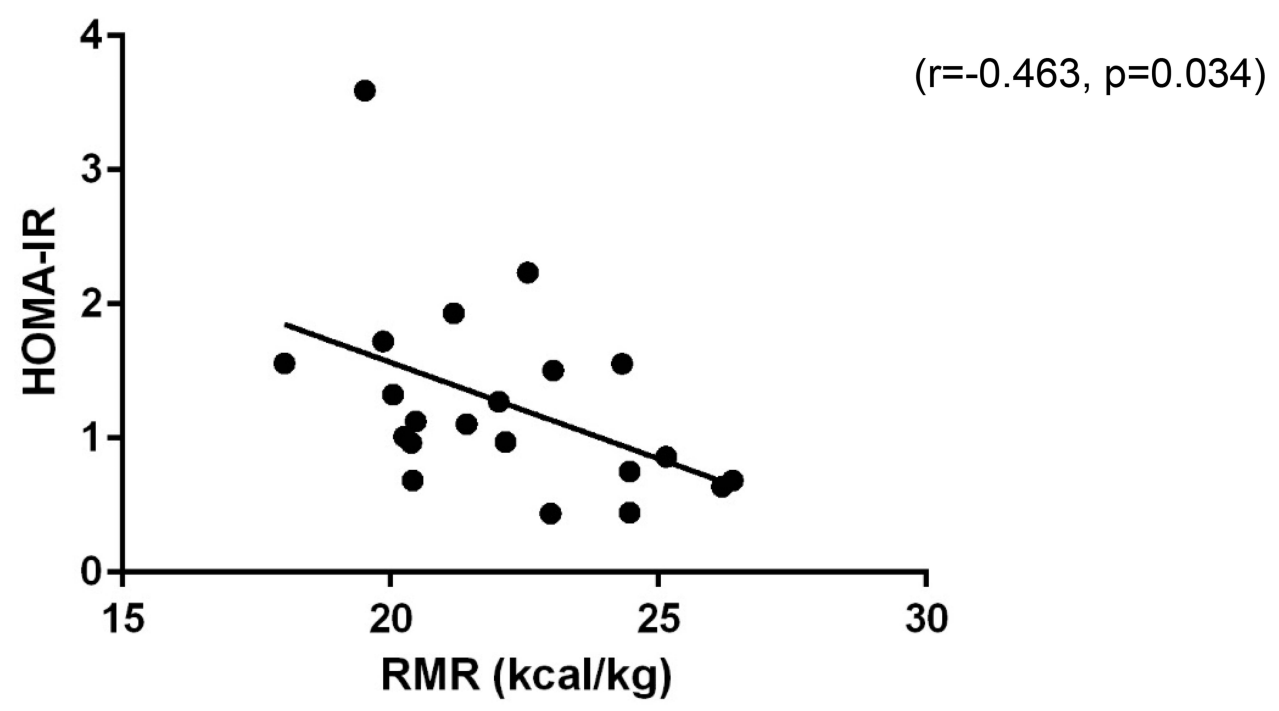

Figure I Relative resting metabolic rate and insulin resistance are negatively correlated at 4-6 months postpartum

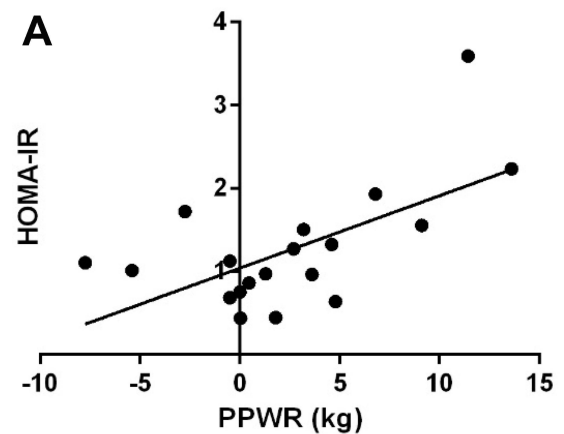

C

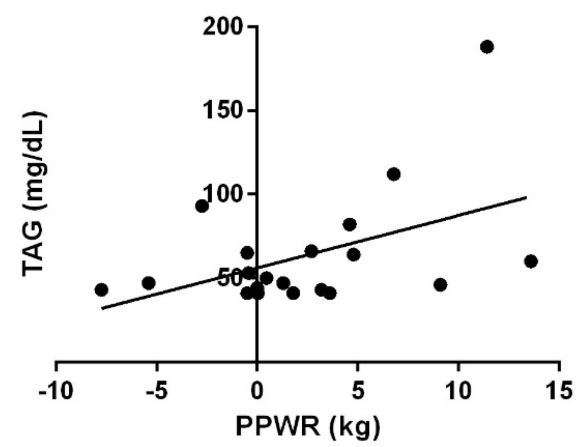

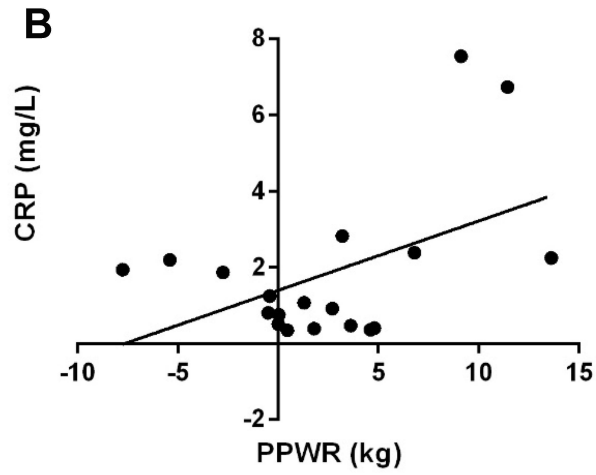

D

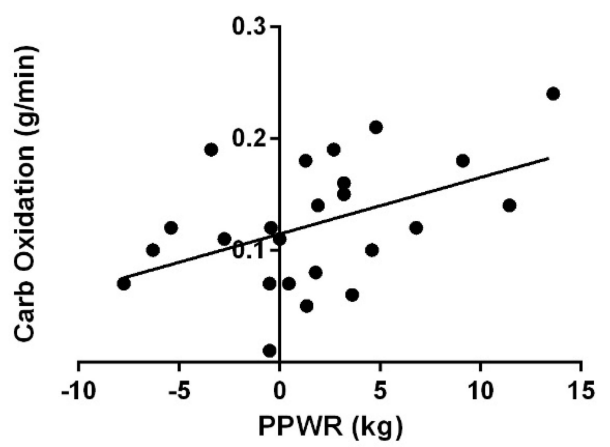

Figure 2 Postpartum weight retention is positively correlated with metabolic outcomes including (A) insulin resistance, (B) inflammation, (C) triglycerides, and (D) carbohydrate oxidation.

suggests that RMR will increase throughout pregnancy and then decrease into the postpartum period in response to changes in body weight status; ${ }^{22,23}$ however, the extent of these changes is poorly understood. The fact that RMR relative to body weight was still different between timepoints is in agreement with Butte et al, who demonstrated a significantly higher RMR for the pregnant women, even when accounting for changes in body weight between the time points. ${ }^{21}$ Given that American women have become less metabolically 
healthy over the past 20 years (ie significantly higher incidence of obesity ${ }^{24}$ and higher incidence of insulin resistance $^{25}$ ), confirmation of findings from the 1999 Butte et al study is important and timely.

Considering that RMR is the largest component of caloric expenditure in humans (irrespective of pregnancy status), a decrease in RMR may predispose one to additional weight gain and/or retention. ${ }^{26}$ Throughout pregnancy, women are recommended to increase their caloric intake to supply the additional caloric requirements of the developing fetus. When transitioning from pregnancy to postpartum, if women do not either decrease their caloric intake or increase their caloric expenditure via physical activity (which our data suggests there was no change in diet or activity levels between pregnant and postpartum), a reduced relative RMR may further enhance the likelihood of postpartum weight retention and possibly even further weight gain after delivery. Lower RMR during into the postpartum period is one factor that could lead to greater problems associated with postpartum weight retention. ${ }^{22}$ Weight retention has been associated with the increased prevalence of obesity ${ }^{27}$ and obesity has been known to increase the risk for a number of chronic adverse health outcomes, such as diabetes, and heart disease. ${ }^{28}$ Therefore, the implications of reduced metabolic function are important to consider from a clinical perspective. Considering that a large proportion of RMR is determined by genetics ${ }^{26}$ it may be important to consider each patient individually in order to determine dietary and exercise guidelines that will work best for them in order to lose or maintain weight during the postpartum period.

Breastfeeding status may play an important role in determining resting metabolic rate as breastfeeding has been shown to increase energy needs substantially. ${ }^{29}$ Our data are consistent with this as RMR was higher among lactating women (compared to non-lactating women) when accounting for body weight $(\mathrm{p}=0.046)$. Given that the majority of our study participants were lactating at the time of assessment, the fact that metabolic rate (adjusted for body weight) was still higher among pregnant women is even more suggestive of unfavorable metabolic changes during the postpartum period that may predispose a woman to weight gain/retention. It is likely that the differences in metabolic rate between pregnancy and postpartum would be even more profound in a cohort of nonlactating women. This is important to note as more than 4 out of 10 infants are no longer breastfed in any capacity by 6 months. ${ }^{30}$ This interpretation is consistent with Stuebe et al who suggests lactation may play an important role in mediating healthy metabolic adaptations (and reduce future health risks) as women transition from pregnancy and postpartum back to normal metabolic status. ${ }^{31}$

Relative resting metabolic rate was positively correlated with maternal HOMA-IR at 4-6 months postpartum. This is important to consider as adults (not pregnant or recently postpartum) with a low basal metabolic rate have a higher propensity for weight gain and insulin resistance. ${ }^{32}$ If not addressed, it is possible that women with lower metabolic rates may be more likely to develop future insulin resistance or type II diabetes.

Another noteworthy finding is that maternal insulin resistance (ie HOMA-IR) was positively correlated to postpartum weight retention $(\mathrm{r}=0.617, \mathrm{p}=0.004)$, and remained correlated when controlling for pre-pregnancy BMI. Soria-Contreras et al found that postpartum weight retention and weight gain during the first year were positively correlated to HOMA-IR at six years postpartum. Another study found that women who gained excess weight from pregnancy to postpartum had a higher risk of gestational diabetes in subsequent pregnancies, ${ }^{33}$ which suggests weight retained after pregnancy is intricately connected to insulin resistance during the months and even years after delivery. Taken together, the relationship noted in the present study may persist well beyond 6-months postpartum and potentially predispose mothers for gestational diabetes and type II diabetes development later in life.

In addition, CRP and postpartum weight retention were positively correlated in the present study. It is wellestablished that obesity contributes to higher levels of systemic inflammation. ${ }^{34}$ It is also well-known that systemic inflammation contributes to cardiovascular disease, type II diabetes, and metabolic disease. ${ }^{34}$ Previous work found that endocrine-disrupting chemicals, which are stronger among obese women, are positively correlated to inflammation in pregnant and postpartum women. ${ }^{35}$ Another study found higher mid-gestation CRP was correlated to gestational weight gain rate; ${ }^{36}$ suggesting an important relationship between weight gain during and after pregnancy and inflammatory profiles. Given the relationship between postpartum weight retention and inflammation noted in the present study, women who retain weight at 4-6-months postpartum may have a more unfavorable inflammatory profile. This may further contribute to poorer cardiometabolic health in the years following pregnancy. 
Similarly, triglyceride levels were positively correlated to postpartum weight retention. This finding is consistent with previous work by Puhkala et al who concluded that postpartum weight retention (specifically, $3.4 \mathrm{~kg}$ or more) is associated with higher triglycerides which contributes to a more atherogenic lipid profile. ${ }^{37}$ Given that insulin resistance, inflammation, and lipids are all related to postpartum weight retention as early as $4-6$ months, and that all of these factors can contribute to short and long-term disease risk, it seems imperative to find ways to limit gestational weight gain, postpartum weight retention, and help women become and stay healthier in the years following childbearing.

A novel finding in the present study is that baseline carbohydrate oxidation at 4-6 months postpartum was related to postpartum weight retention. Individuals with increased carbohydrate oxidation have lower carbohydrate stores (as more are being oxidized for sustaining energy). ${ }^{38} \mathrm{~A}$ low carbohydrate reserve has been associated with increased weight gain. ${ }^{38}$ It is plausible that a similar phenomenon is occurring during the postpartum period where carbohydrate oxidation could be contributing to weight gain and/or retention. Patterns of substrate oxidation during the postpartum period may shed important light on metabolic factors contributing to weight retention, which may then have implications for inflammation, insulin resistance, and lipid profiles; however, more research is needed in this area.

The long-term implications of this research are substantial when the lifetime of each mother is considered. Most women go through pregnancy and postpartum more than one time. Gestational weight gain is the strongest predictor of postpartum weight retention. ${ }^{39}$ Further, gestational weight gain in a woman's first pregnancy is a significant predictor of weight gain in her subsequent pregnancies. ${ }^{40}$ Thus, if a woman gains weight during pregnancy, retains it during postpartum, becomes pregnant again and repeats this cycle, over a 5-10 year period, she may experience considerable weight gain, retention, and put herself at significantly increased risk of long-term disease. It is well-established that excess weight gain during pregnancy, followed by a failure to lose the weight during postpartum, is a strong predictor of long-term obesity. ${ }^{41}$ The cumulative effect of excess weight gain during pregnancy (and subsequent retention postpartum) contributes to long-term metabolic and cardiovascular disease risk. ${ }^{42}$ Understanding the mechanisms that perpetuate the cycle of weight gain, weight retention, and increased disease risk during and after pregnancy will provide the potential to alter this cycle and improve long-term health.

\section{Conclusion}

The American College of Obstetricians and Gynecologists (ACOG) have issued a committee report verifying the need for a paradigm shift to optimize postpartum care including more resources and medical care for women during the first year postpartum. ${ }^{43}$ This research further supports that notion that postpartum is a vulnerable time and weight gain and retention during this time should not be ignored. Data from the present study suggest metabolic adaptations during this time period may make women particularly vulnerable to weight gain and retention, and that this weight retention may put women at risk for a future long-term cardiovascular and metabolic disease. Additional studies about mechanisms underlying postpartum metabolism are warranted. Further, additional evidence-based resources for women to return to a healthy body weight are needed.

\section{Data Sharing Statement}

The datasets generated and analyzed during the current study are available from the corresponding author upon reasonable request.

\section{Ethics Approval}

This study was reviewed and approved by Western Kentucky University's Institutional Review Board (IRB: 19-413). The study was conducted in accordance with the Declaration of Helsinki.

\section{Consent to Participate}

All participants read and signed an informed consent document before study participation began.

\section{Funding}

This study was funded by the NIGMS-funded Institutional Development Award (IDeA) Networks of Biomedical Research Excellence (INBRE) in Kentucky (P20GM103436) and Western Kentucky University Research and Creative Activities Program Grant.

\section{Disclosure}

The authors have no relevant financial or non-financial interests to disclose. 


\section{References}

1. Reece EA, Leguizamon G, Wiznitzer A. Gestational diabetes: the need for a common ground. Lancet. 2009;373(9677):1789-1797. doi:10.1016/S0140-6736(09)60515-8

2. Chan JC, Malik V, Jia W, et al. Diabetes in Asia: epidemiology, risk factors, and pathophysiology. JAMA. 2009;301(20):2129-2140. doi:10.1001/jama.2009.726

3. Godfrey KM, Reynolds RM, Prescott SL, et al. Influence of maternal obesity on the long-term health of offspring. Lancet Diabetes Endocrinol. 2017;5(1):53-64. doi:10.1016/S2213-8587(16)30107-3

4. Pastore I, Chiefari E, Vero R, Brunetti A. Postpartum glucose intolerance: an updated overview. Endocrine. 2017.

5. Rasmussen KM, Catalano PM, Yaktine AL. New guidelines for weight gain during pregnancy: what obstetrician/gynecologists should know. Curr Opin Obstet Gynecol. 2009;21(6):521-526. doi:10.1097/GCO.0b013e328332d24e

6. Dalenius K, Brindley P, Smith B, Reinold C, Grummer-Strawn L. Pregnancy Nutrition Surveillance 2010 Report. Atlanta: U.S. Department of Health and Human Services, Centers for Disease Control and Prevention; 2012.

7. Rooney BL, Schauberger CW, Mathiason MA. Impact of perinatal weight change on long-term obesity and obesity-related illnesses. Obstet Gynecol. 2005;106(6):1349-1356. doi:10.1097/01. AOG.0000185480.09068.4a

8. Lain KY, Catalano PM. Metabolic changes in pregnancy. Clin Obstet Gynecol. 2007;50(4):938-948. doi:10.1097/GRF.0b013e31815a5494

9. Wendland CL. The vanishing mother: cesarean section and "evidence-based obstetrics". Med Anthropol Q. 2007;21(2):218-233. doi:10.1525/maq.2007.21.2.218

10. Pereira LCR, Elliott SA, McCargar LJ, et al. The influence of energy metabolism on postpartum weight retention. Am J Clin Nutr. 2019;109(6):1588-1599. doi:10.1093/ajcn/nqy389

11. Berggren EK, Presley L, Amini SB, Hauguel-de Mouzon S, Catalano PM. Are the metabolic changes of pregnancy reversible in the first year postpartum? Diabetologia. 2015;58(7):1561-1568. doi:10.1007/s00125-015-3604-x

12. Saade GR. Pregnancy as a window to future health. Obstet Gynecol. 2009;114(5):958-960. doi:10.1097/AOG.0b013e3181bf5588

13. Tinius RA, Blankenship MM, Furgal KE, et al. Metabolic flexibility is impaired in women who are pregnant and overweight/obese and related to insulin resistance and inflammation. Metabolism. 2020;104:154142. doi:10.1016/j.metabol.2020.154142

14. Frayn KN. Calculation of substrate oxidation rates in vivo from gaseous exchange. J Appl Physiol Respir Environ Exerc Physiol. 1983;55(2):628-634. doi:10.1152/jappl.1983.55.2.628

15. Huston presley L, Wong WW, Roman NM, Amini SB, Catalano PM. Anthropometric estimation of maternal body composition in late gestation. Obstet Gynecol. 2000;96(1):33-37. doi:10.1016/S00297844(00)00857-7

16. Marshall NE, Murphy EJ, King JC, et al. Comparison of multiple methods to measure maternal fat mass in late gestation. Am J Clin Nutr. 2016;103(4):1055-1063. doi:10.3945/ajcn.115.113464

17. Widen EM, Gallagher D. Body composition changes in pregnancy: measurement, predictors and outcomes. Eur J Clin Nutr. 2014;68 (6):643-652. doi:10.1038/ejen.2014.40

18. Qiu C, Gelaye B, Zhong QY, Enquobahrie DA, Frederick IO, Williams MA. Construct validity and factor structure of the Pittsburgh Sleep Quality Index among pregnant women in a Pacific-Northwest cohort. Sleep Breath. 2016;20(1):293-301. doi:10.1007/s11325-016-1313-4

19. Ceneters for Disease Control. Questionnaires: breastfeeding and Infant Feeding Practices. 5 month postpartum survey. Available from: https://www.cdc.gov/breastfeeding/data/ifps/questionnaires. htm. Accessed November 4, 2020.
20. Gibson J, McKenzie-McHarg K, Shakespeare J, Price J, Gray R. A systematic review of studies validating the Edinburgh Postnatal Depression Scale in antepartum and postpartum women. Acta Psychiatr Scand. 2009;119(5):350-364. doi:10.1111/j.16000447.2009.01363.x

21. Butte NF, Hopkinson JM, Mehta N, Moon JK, Smith EO. Adjustments in energy expenditure and substrate utilization during late pregnancy and lactation. Am J Clin Nutr. 1999;69(2):299-307. doi:10.1093/ajen/69.2.299

22. Melzer K, Schutz Y, Soehnchen N, et al. Prepregnancy body mass index and resting metabolic rate during pregnancy. Ann Nutr Metab. 2010;57(3-4):221-227. doi:10.1159/000322369

23. Kopp-Hoolihan LE, van Loan MD, Wong WW, King JC. Longitudinal assessment of energy balance in well-nourished, pregnant women. Am J Clin Nutr. 1999;69(4):697-704. doi:10.1093/ajen/ 69.4.697

24. Hales CM, Carroll MD, Fryar CD, Ogden CL. Prevalence of Obesity and Severe Obesity Among Adults: United States, 2017-2018. NCHS Data Brief, No 360. Hyattsville, MD: National Center for Health Statistics; 2020.

25. Centers for Disease Control and Prevention. National Diabetes Statistics Report, 2020. Atlanta, GA: Centers for Disease Control and Prevention, U.S. Dept of Health and Human Services; 2020.

26. Ravussin E. Low resting metabolic rate as a risk factor for weight gain: role of the sympathetic nervous system. Int J Obes Relat Metab Disord. 1995;19(Suppl 7):S8-S9.

27. Leddy MA, Power ML, Schulkin J. The impact of maternal obesity on maternal and fetal health. Rev Obstet Gynecol. 2008;1 (4):170-178.

28. Caballero AE. Endothelial dysfunction in obesity and insulin resistance: a road to diabetes and heart disease. Obes Res. 2003;11 (11):1278-1289. doi:10.1038/oby.2003.174

29. Motil KJ, Montandon CM, Garza C. Basal and postprandial metabolic rates in lactating and nonlactating women. Am J Clin Nutr. 1990;52(4):610-615. doi:10.1093/ajen/52.4.610

30. Breastfeeding Report Card. Centers for Disease Control; 2018. Available from: https://www.cdc.gov/breastfeeding/data/reportcard. htm. Accessed May 31, 2021.

31. Stuebe AM, Rich-Edwards JW. The reset hypothesis: lactation and maternal metabolism. Am $J$ Perinatol. 2009;26(1):81-88. doi:10.1055/s-0028-1103034

32. Maciak S, Sawicka D, Sadowska A, et al. Low basal metabolic rate as a risk factor for development of insulin resistance and type 2 diabetes. BMJ Open Diabetes Res Care. 2020;8(1):1. doi:10.1136/ bmjdrc-2020-001381

33. Liu J, Song G, Meng T, Zhao G, Guo S. Weight retention at six weeks postpartum and the risk of gestational diabetes mellitus in a second pregnancy. BMC Pregnancy Childbirth. 2019;19(1):272. doi:10.1186/s12884-019-2423-3

34. Brooks GC, Blaha MJ, Blumenthal RS. Relation of C-reactive protein to abdominal adiposity. Am $J$ Cardiol. 2010;106(1):56-61. doi:10.1016/j.amjcard.2010.02.017

35. Zota AR, Geller RJ, Romano LE, et al. Association between persistent endocrine-disrupting chemicals (PBDEs, OH-PBDEs, PCBs, and PFASs) and biomarkers of inflammation and cellular aging during pregnancy and postpartum. Environ Int. 2018;115:9-20. doi:10.1016/ j.envint.2018.02.044

36. Perng W, Rifas-Shiman SL, Rich-Edwards JW, Stuebe AM, Oken E. Inflammation and weight gain in reproductive-aged women. Ann Hum Biol. 2016;43(1):91-95. doi:10.3109/ 03014460.2014.968619

37. Puhkala J, Luoto R, Ahotupa M, Raitanen J, Vasankari T. Postpartum weight retention is associated with elevated ratio of oxidized LDL lipids to HDL-cholesterol. Lipids. 2013;48(12):1227-1235. doi:10.1007/s11745-013-3852-9 
38. Galgani J, Ravussin E. Energy metabolism, fuel selection and body weight regulation. Int $J$ Obes. 2008;32(Suppl 7):S109-119. doi:10.1038/ijo.2008.246

39. Rong K, Yu K, Han X, et al. Pre-pregnancy BMI, gestational weight gain and postpartum weight retention: a meta-analysis of observational studies. Public Health Nutr. 2015;18(12):2172-2182. doi:10.1017/S1368980014002523

40. Chin JR, Krause KM, Ostbye T, Chowdhury N, Lovelady CA, Swamy GK. Gestational weight gain in consecutive pregnancies. Am J Obstet Gynecol. 2010;203(3):279 e271-276. doi:10.1016/j. ajog.2010.06.038
41. Rooney BL, Schauberger CW. Excess pregnancy weight gain and long-term obesity: one decade later. Obstet Gynecol. 2002;100 (2):245-252. doi:10.1016/s0029-7844(02)02125-7

42. Kew S, Ye C, Hanley AJ, et al. Cardiometabolic implications of postpartum weight changes in the first year after delivery. Diabetes Care. 2014;37(7):1998-2006. doi:10.2337/dc14-0087

43. ACOG Committee Opinion. No. 736: optimizing Postpartum Care. Obstet Gynecol. 2018;131(5):e140-e150. doi:10.1097/ AOG.0000000000002633

\section{Publish your work in this journal}

The International Journal of Women's Health is an international, peerreviewed open-access journal publishing original research, reports, editorials, reviews and commentaries on all aspects of women's healthcare including gynecology, obstetrics, and breast cancer. The manuscript management system is completely online and includes a very quick and fair peer-review system, which is all easy to use. Visit http://www.dovepress.com/testimonials.php to read real quotes from published authors. 